\title{
Discursos sobre gênero e sexualidade no Facebook
}

Gender and Sexuality Discourses on Facebook Discursos sobre género y sexualidad en Facebook

Laura Peretto Salerno' (iD 0000-0001-5937-892X

'Universidade Federal de Santa Catarina, Programa de Pós-Graduação em Educação, Florianópolis, SC, Brasil.88040-900 - ppge@contato.ufsc.br

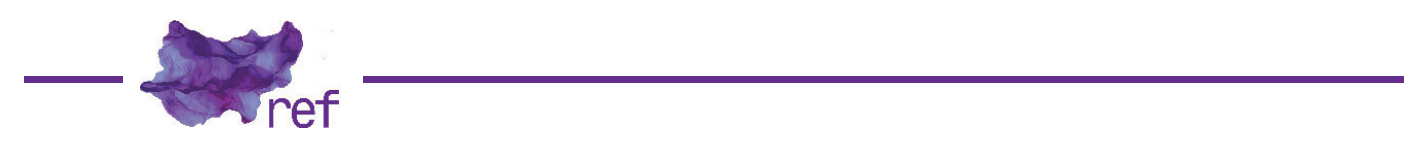

MORATO, Rafael.

Gênero, sexualidade e redes sociais: a desigualdade social "curtida" e "compartilhada".

Belo Horizonte: Letramento, 2019.

O livro aqui resenhado foi publicado em 2019, mas as questões que ele nos traz fazem pensar que estamos séculos atrás. Como é possível ainda nos depararmos com o fato de que a nossa sociedade vive para criticar e aprovar a sexualidade e os comportamentos do outro? Estamos na chamada era digital, em que as redes sociais atuam com força e protagonismo nas interações humanas, cada curtida ou compartilhamento feito nesses meios digitais carrega consigo uma carga ideológica muito grande, julgando comportamentos e influenciando opiniões.

Nesse universo de possibilidades que a vida, o corpo humano e as relações sociais nos apresentam, há inúmeras formas de ser e de viver os gêneros e a sexualidade. No entanto, o que se percebe através de redes sociais como o Facebook, por exemplo, é que continuamos nos apegando a críticas pautadas na dualidade, que giram em torno de um modelo de homem e de mulher socialmente construídos, e de uma sexualidade baseada na heteronormatividade, invisibilizando - e muitas vezes condenando - outras formas possíveis de ser e de se relacionar emocional e sexualmente.

É sobre isso que Rafael dos Santos Morato (2019) procura discutir em seu livro Gênero, sexualidade e redes sociais: a desigualdade social "curtida" e "compartilhada". Lançado pela editora Letramento, é fruto de sua pesquisa de Mestrado em Direitos Humanos pela Universidade Federal de Pernambuco e traz à tona a questão dos discursos acerca de gênero e sexualidade presentes em comentários das postagens feitas na página do Facebook intitulada "Humaniza Redes". A escolha pela referida página foi justificada por ser direcionada à discussão da humanização nas mídias, da cidadania LGBT e da equidade de gênero.

Nos dois capítulos iniciais - "O discurso e as relações sociais" e "Poder e ideologia" -, o autor trata da importância de se compreender os discursos para que seja possível desvelar o que está por detrás das postagens da página, bem como dos comentários realizados pelos usuários 
após lerem essas postagens. A partir da compreensão de que discurso, ideologia e poder estão fortemente imbricados, Morato se utiliza das ferramentas da Análise de Discurso Crítica (ADC) para buscar alcançar os sentidos ideológicos que moldam e influenciam os discursos sobre gênero e sexualidade na página Humaniza Redes, bem como para tentar desvelar os elementos subjacentes a eles.

Uma vez compreendido que o poder se exerce e funciona em rede (Michel FOUCAULT, 1979), de maneira que para a Análise de Discurso Crítica o poder se dá a partir da capacidade do controle da produção e distribuição de textos em determinados contextos socioculturais, fica claro que uma desigual distribuição de poder gera fortes formas de opressão e dominação, ainda que venham através de discursos proferidos em redes sociais. Assim como o que é dito, os silenciamentos também possuem um papel importante na interpelação dos sujeitos no que diz respeito à constituição dos sentidos dos discursos.

Ao abordar o conceito de gênero no terceiro capítulo "Gênero: entender para não temer", Rafael Morato o faz traçando um apanhado histórico de como emergiram os estudos de gênero, buscando destacar sua relevância social para a compreensão de que os padrões de comportamento associados ao que significa ser mulher e homem, em nossa sociedade, são socialmente construídos e contribuem fortemente para a articulação e significação do poder, para a garantia de privilégios e manutenção de conflitos sociais. Para tratar dessa questão, dialoga com importantes autoras, como Joan Scott, Gayle Rubin e Judith Butler.

Ao voltar o olhar para a população LGBT, o autor busca enfatizar a concepção problematizada por Butler (2003) de que não apenas o gênero, mas também o sexo, são categorias construídas discursiva e socialmente. E a questão chave, ao encarar os papéis de gênero como duais (masculino/feminino), é que a inteligibilidade social acaba por afetar também a sexualidade das pessoas, pois da mesma forma que os padrões normativos determinam o que é ser homem ou mulher, determinam também quais os comportamentos sexuais são socialmente aceitáveis.

Ao mesmo tempo, ao dicotomizar a sexualidade em hetero e homo, só se consegue reforçar a homossexualidade como sendo um contraponto da heterossexualidade, que é vista como normal e natural. E parece que o que se intenta com receitas comportamentais, é invisibilizar as diversas possibilidades de ser e de viver a sexualidade, relegando o diferente do padrão heteronormativo a um papel de anormal ou antinatural. É com essa discussão que o autor inicia o quarto capítulo, intitulado "Sexualidade: a luta pela liberdade de desejar", no qual afirma que muitas vezes lésbicas, gays, travestis, bissexuais e transexuais reproduzem comportamentos heteronormativos para se sentirem socialmente aceitos, o que acaba por reforçar ainda mais a preeminência da heterossexualidade.

Se se entende que não existem normas ou classificações que consigam abarcar todas as possibilidades presentes na sexualidade humana, entende-se também que é mister romper com as categorias dicotômicas e uniformizadoras para dar espaço à fluidez dos comportamentos sexuais. Para tanto, é preciso mudar os discursos que reproduzem visões hegemônicas sobre condutas sociais e sexuais, e que se constroem baseados numa compreensão heteronormativa sobre o que significa ser homem ou mulher. Ademais, a maneira como tais conceitos são elaborados e difundidos através dos discursos, principalmente aqueles veiculados nas mídias e redes sociais, contribui demasiadamente para alicerçar situações de opressão e de hierarquias sociais. Assim, os discursos acerca de gênero e sexualidade motivam ao quinto capítulo do livro - "Gênero, sexualidade e linguagem - a boca fala do que a trajetória tá cheia" -, levando a um entendimento de como os sujeitos se constituem através dos recursos linguísticos e de como produzem diferenças entre os gêneros (Deborah CAMERON, 2010).

A partir disso, Morato passa a analisar os discursos produzidos através de postagens e comentários publicados na página do Humaniza Redes, no Facebook. Atentando para o papel e a força das mídias e, mais recentemente, das redes sociais para a formação de subjetividades, o autor procura mostrar o quanto e de que forma os discursos de ódio, de LGTBfobia, de preconceito de gênero e de heteronormatividade estão presentes nesses espaços de comunicação.

A partir das análises das postagens e comentários, o livro traz importantes questões para reflexão, dentre as quais está a sensação de anonimato trazida pelas mídias sociais, o que potencializa a veiculação de discursos carregados de ódio e de ideologias a favor da manutenção das relações de poder hegemônicas, bem como da inteligibilidade heteronormativa.

Por sua vez, tais enunciações, que carregam consigo uma performatividade de gênero, contribuem na constituição dos sujeitos, podendo afirmar, assim, que masculinidades, feminilidades e sexualidades são construídas através da produção e reprodução desses discursos. De tal modo, descontruir os padrões binários e heteronormativos que constituem esses discursos hegemônicos é imprescindível já que, conforme aponta Butler (2003), mudanças discursivas levam a mudanças sociais. 


\section{Referências}

BUTLER, Judith. Problemas de gênero: feminismo e subversão da identidade. Trad. de Renato Aguiar. Rio de Janeiro: Civilização Brasileira, 2003.

CAMERON, Deborah. "Desempenhando identidade de gênero: conversa entre rapazes e construção da masculinidade heterossexual". In: OSTERMANN, Ana Cristina; FONTANA, Beatriz (org.). Linguagem, gênero, sexualidade: clássicos traduzidos. São Paulo: Parábola, 2010. p. 129149.

FOUCAULT, Michel. Microfísica do poder. Trad. de Roberto Machado. Rio de Janeiro: Edições Graal, 1979.

MORATO, Rafael. Gênero, sexualidade e redes sociais: a desigualdade social "curtida" e "compartilhada". Belo Horizonte: Letramento, 2019.

Laura Peretto Salerno (laurapedagog@gmail.com) é doutoranda em Educação pela Universidade Federal de Santa Catarina. Mestre em educação pela Universidade do Estado de Santa Catarina (2009). Especialista em Currículo e Cultura pela Universidade do Estado de Santa Catarina (2003) e em Educação Sociedade e Cultura pela Fundação Universidade de Blumenau (2008). Tem experiência na área de Educação, com ênfase em Currículo, Gênero e Sexualidade.

COMO CITAR ESTE ARTIGO DE ACORDO COM AS NORMAS DA REVISTA

SALERNO, Laura Peretto. "Discursos sobre gênero e sexualidade no Facebook". Revista Estudos Feministas, Florianópolis, v. 30, n. 1, e79552, 2022.

\section{CONTRIBUIÇĀO DE AUTORIA}

Não se aplica.

\section{FINANCIAMENTO}

Não se aplica.

\section{CONSENTIMENTO DE USO DE IMAGEM}

Não se aplica.

\section{APROVAÇĀO DE COMITÊ DE ÉTICA EM PESQUISA}

Não se aplica.

\section{CONFLITO DE INTERESSES}

Não se aplica.

\section{LICENÇA DE USO}

Este artigo está licenciado sob a Licença Creative Commons CC-BY 4.0 International. Com essa licença você pode compartilhar, adaptar, criar para qualquer fim, desde que atribua a autoria da obra.

\section{HISTÓRICO}

